\title{
Noise Induced Hearing Loss in Military Helicopter Aircrew - A Review of the Evidence
}

\author{
Maj JP Owen \\ $\mathrm{MB}, \mathrm{ChB}, \mathrm{AFOM}, \mathrm{RAMC}{ }^{*}$ \\ Institute of Occupational Health, University of Birmingham, Edgbaston, Birmingham B15 2TT
}

SUMMARY: Noise Induced Hearing Loss (NIHL) has been recognised for some time. In the military environmōint one group of personnel at risk are Army helicopter aircrew who are exposed to continuous noise levels of up to 面0 $\mathrm{dB}(\mathrm{A})$ in flight. The evidence for the damaging effect of this occupational noise is reviewed and some of the difficulties in drawing conclusions are highlighted. The current protection offered for the Mk 4 helmet is discussed and the incorporation of Active Noise Reduction (ANR) is suggested as a likely way of ensuring that the in-flight noise exposure in Army aircrew is kept as low as possible.

\section{Introduction}

The detrimental effects of noise on hearing have been known for a long time. In 50 AD Pliny the Elder reported in his Natural History that people living near one of the roaring cataracts of the Nile became hard of hearing. This is perhaps one of the earliest references to the detrimental effects of continuous noise exposure. Ramazzini (1) noted in 1713 that coppersmiths hammering copper "have their ears so injured by this perpetual din .... that workers of this class become hard of hearing and, if they grow old at this work, perpetually deaf, highlighting the deleterious effects of repetitive impulsive noise. Despite the awareness that exposure to noise was detrimental to hearing, very little was done to reduce the noise or protect the workers, as shown in the Chief Inspector of Factories and Workshops' Annual Report (2) in 1934, which commented, 'Only in comparatively few cases do the workers appear conscious of any inconvenience sufficient to justify the wearing of ear protection'.

Since the Second World War awareness of hearing damage caused by noise has increased greatly, culminating in the Noise at Work Regulations 1990 (3). These regulations set two action levels for noise exposure. The first action level for an $8 \mathrm{hr}$ exposure is $85 \mathrm{~dB}(\mathrm{~A}) \mathrm{Leq}$, above which hearing protection must be available if requested and the second is $90 \mathrm{~dB}(\mathrm{~A})$ Leq, above which hearing protection must be used and the noise level must be reduced as far as reasonably practicable. The regulations apply to all workers in the United Kingdom, including service personnel and civilians employed by the Ministry of Defence, who are exposed in the military environment to a mixture of impulsive (gunfire) and continuous (machinery) noise.

Military aircrew are one of the groups exposed to continuous noise above the limits recognised to cause hearing damage. One for the first studies into deafness in aviators was carried out in 1939 and showed a hearing loss related to exposure to piston engine noise which was diminished by the use of hearing protection (4). Further studies were carried out and by 1953 it was suggested that
$90 \mathrm{~dB}$ should be the danger level for noise exposure $\frac{}{\mathrm{W5}}$ ).

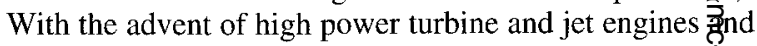
the requirement for faster, lighter and more manoeuverable aircraft the noise load has continuefto rise.

A good level of hearing acuity is important in piłts and aircrew because, after visual input, auditgry information provides the greatest degree of assistane in flying the aircraft safely. Despite the noisy envirogment the aircrew need to use an extensive communigitifon system, from the personal communication witho the cockpit (intercom) to the radio systems (in the mifigry environment this may involve the concurrent use oftkree radios) and the auditory warning signals such as the dio altimeter and the radar warning receiver. This equiont is used during flight when the aircrew are us involved in other activities which may be highly stres In addition to this the quality of the radio information be poor with interference and static noise partigifly masking the messages.

In view of the difficulty in assimilating auditgry information it would not be unreasonable to wish to a apid exacerbating the problem of impaired hearing, especiontly as in-flight errors may be fatal. One of the few studie to look at the effect of impaired hearing on flight safety as done in 1981 (6). The accident rates were examined fop 70 US Army aviators who had impaired hearing belowgthe normally acceptable limit but were still flying followi medical examination and issue of a waiver. They fognd no relationship between accident rates and impaixed hearing in this group and concluded that the evaluaton appeared sensitive enough to recognise those who were medically safe to continue flying, as their acquired flying skills appeared to compensate for the hearing loss.

\section{Risks and Sources of Noise Exposure}

Aircrew have some noise exposure within squadron buildings and when carrying out daily inspections on aircraft. However the principle exposure occurs when flying and is predominantly low frequency ẩnd 
mechanical in origin. For example, in the 'Lynx' the lower frequencies $(0-250 \mathrm{~Hz})$ are dominated by main and tail rotor noise, while the mid-frequencies $(300-4000 \mathrm{~Hz})$ are dominated by gearbox noise (7). In 1977, in a study of military helicopter aircrew, the average 'noise at the ear levels' were measured in a selection of Service helicopters and found to be $97 \mathrm{~dB}(\mathrm{~A})$ for the 'Gazelle', $99.8 \mathrm{~dB}(\mathrm{~A})$ for the 'Scout' and $99.9 \mathrm{~dB}(\mathrm{~A})$ for the 'Puma' (8). A further survey in 1981 showed average noise at the ear levels in the 'Lynx' to be $100 \mathrm{~dB}(\mathrm{~A})(7)$.

The other major sources of noise are both wanted and unwanted signals from the communications systems. In 1977 work at the Royal Aircraft Establishment showed that aircrew are exposed to communications noise from -an average of $40 \%$ of each sortie, increasing the noise dose from the aircraft noise alone by about $6 \mathrm{~dB}$ (9). Since then, an increased number of in-flight radios and acoustic warning signals have been fitted, increasing the noise load from the communications systems.

The effects of noise exposure at these levels have been studied in several countries with a variety of conclusions between hearing loss and number of years spent flyi (12). In 1985, however, Ribak et al, studying $7 \% 7$ personnel in the Israeli Air Force, had shown a stro relationship between age and hearing threshold shift, while flying time and aircraft type were only pooroly related (13). One of the most recent studies carried out in the UK military environment was by Jones in the Royal Navy (14). This showed that NIHL did not appear to benat problem for aircrew with less than ten years flyig experience, given the current number of hours flown eaeh year.

The differing conclusions drawn from the studies citod above show some of the difficulties in trying to drawga straightforward relationship when there are sever 1 influencing factors. The principle confounding factor thet needs to be taken into account is the natural effect $\vec{f} \overrightarrow{\mathrm{or}}$ presbyacusis. There is also the effect of improved heariog protection provided by modern aircrew helme combined with a reduction in the number of hours spemt flying due to financial and training constraints, whigh result in a different noise dose over the years. TI

Table 1

Summary of Studies of Hearing Loss in

Military Aircrew

\begin{tabular}{|c|c|c|c|c|c|c|c|c|c|}
\hline \multirow[t]{2}{*}{ Year } & \multirow{2}{*}{$\begin{array}{l}\text { Author } \\
\text { (First only) }\end{array}$} & \multirow{2}{*}{$\begin{array}{l}\text { No. in } \\
\text { Study }\end{array}$} & \multirow{2}{*}{$\begin{array}{l}\text { Mean } \\
\text { Age } \\
\text { (Years) }\end{array}$} & \multirow{2}{*}{$\begin{array}{l}\text { Av. Flt } \\
\text { Hours }\end{array}$} & \multicolumn{4}{|c|}{ Correlation with Hearing Threshold Shift } & \multirow{2}{*}{ 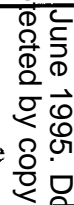 } \\
\hline & & & & & Age & $\begin{array}{l}\text { Years } \\
\text { Flying }\end{array}$ & $\begin{array}{l}\text { Total } \\
\text { Flight } \\
\text { Hours }\end{array}$ & $\begin{array}{l}\text { A/C } \\
\text { Type }\end{array}$ & \\
\hline 1982 & Edgington & 200 & 31 & $\begin{array}{l}1000- \\
1500\end{array}$ & + & + & - & - & 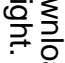 \\
\hline 1983 & Peters & 145 & 32 & $\begin{array}{l}2000- \\
3000\end{array}$ & & & + & & ำ \\
\hline 1985 & Ribak & $777 *$ & 27 & $\begin{array}{l}1000- \\
1500\end{array}$ & +++ & & $+/-$ & $+1-$ & $\overrightarrow{\bar{n}}$ \\
\hline 1988 & Fitzpatrick & 178 & 32 & $1000-$ & $+1-$ & & +++ & - & 3 \\
\hline 1988 & Jones & $184^{*}, \$$ & & $1000-$ & - & + & & - & 竞 \\
\hline
\end{tabular}

*Both Rotary and Fixed Wing Aircrew

$\$$ Includes Pilots, Aircrew, Observers, Photographers and Maintainers.

$+++=$ Strong association

$+\quad=$ Slight association

$+/-\quad=$ Minimal association

- $\quad$ No association

(Table 1). In 1983 a study of US Army aviators at Fort Rucker showed an association between the number of flight hours and an increase in hearing loss (10). A study of 178 helicopter pilots in the US Army by Fitzpatrick in 1988 concluded that hearing loss in aviators was a function of their noise exposure, as expressed by the number of flying hours completed (11). A similar earlier study of 200 helicopter aircrew in the Army Air Corps carried out by Edgington has also shown a relationship technological advancements in the methods for measurieg hearing by audiograms have also changed over the sans period, automatic recording and self-calibratig audiometers in acoustically screened booths replacing recording machines. When the effects of exposure to impulsive noise from firing military weapons are adda the final relationship between hearing impairment ang military flying becomes even more difficult to verify. 


\section{Hearing Protection}

The aircrew helmet provides both impact and acoustic protection and in common with all equipment used in aircraft has to undergo rigorous testing to achieve airworthiness clearance. The noise attenuation characteristics for the Mk 4 helmet, currently in use with British military aircrew, have been extensively studied $(15,16,17)$. The noise attenuation varies with frequency as shown in Figure 1 (17).

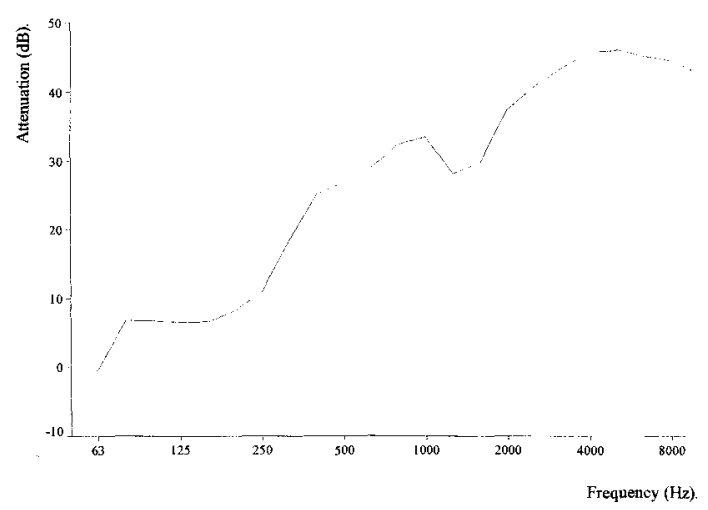

(Attenuation in Decibels, Frequency in Hertz) Fig 1. Noise Attenuation Characteristics of the Mark 4 Helmet

However, as described above, the helmet is also a source of noise from the communications loudspeakers in the earcups. One way of reducing the unwanted communication noise is with electronic filters, however this has the disadvantage of reducing the intelligibility of the information being passed. To get around this problem active noise reduction (ANR) systems have been developed for use in aircrew helmets, in which the acoustic field inside the earcup is detected and an antiphase signal fed back into the cup to cancel out some of the sound energy. This system has been shown to work particularly well in the low frequency range from $40 \mathrm{~Hz}$ to $1 \mathrm{kHz}$, with the mean peak attenuation level of $22.5 \mathrm{~dB}$ occurring in the $315 \mathrm{~Hz} 1 / 3$ octave band (18). As shown in the graph in Figure 1, the low frequency noise attenuation of the Mk 4 helmet is not good, ranging from nil to $33.4 \mathrm{~dB}$ over the same frequency as above, with a mean peak attentuation level of $18.3 \mathrm{~dB}$ at $315 \mathrm{~Hz}$. The combination of the Mk 4 helmet, providing good high frequency protection and ANR increasing the low frequency attenuation ensures that the wearer receives maximum heating protection across all frequencies.

As with all forms of personal protective equipment (PPE), the hearing protection of the helmet will be compromised by poor fitting and incorrect use. All aircrew have their helmets fitted by trained staff and have to have the fit regularly checked as part of the routine helmet servicing. Under certain circumstances aircrew allowed to wear prescription glasses for flying. In these people there is a potential for compromising the earcipp seal with the side arm of the glasses, though this problem is minimised by using glasses with a low profile $6 t$. Another cause of diminished protection is excessige helmet movement on the head. When aircrew are using night vision goggles (NVG) the equipment is mounted the helmet, increasing the weight and moment around the head. NVGs also reduce the field of vision for the wearor, making increased head movements a necessity for safe flight observations. Both of these factors are unavoida aspects of current flying and are addressed by the regudar servicing and inspection of the helmets.

\section{Conclusions}

Army aircrew are operating in an extremely no $\overrightarrow{0}$ y environment in which the principle form of heari $\mathrm{g} g$

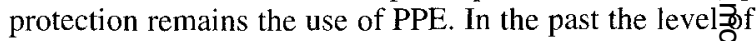
protection provided in this way has not been sufficient ito prevent NIHL. However more recent studies, such as those by Ribak and Jones $(13,14)$, have shown that NI热 in aircrew is becoming less marked and more difficult 100 differentiate from the natural process of presbyacusis.

This is principally due to improved helmet desigñand awareness of the need to comply with hearing proteotion measures. Part of the increased awareness is due to $\$$ annual aircrew medical examination which inclu\& $\$$ pure tone audiogram. The continuing Army He $\overrightarrow{9}+\vec{i} \dot{g} g$ Conservation Program (19) also promotes a gemecoil awareness of the detrimental effects of noise expositie and the irreversible nature of the hearing damage caused.

The mechanical noise generated by helicopters canaiot be greatly altered as the weight burden of any significant amount of sound insulation would cause an unacceptage loss of aircraft performance. Therefore the only realis $9 \mathrm{c}$ method of reducing noise exposure to the aircrew is through the use of PPE, the aircrew helmet, which been correctly fitted and serviced. The combinationjef good high frequency attenuation provided in the curre Mk 4 helmet together with the low frequency cancellation available through the use of ANR provides maxim protection to the aircrew. In addition to these measurgs, the constraints of flight training time and the continumg development of flight simulators should further reduce the noise exposure for aircrew to level where the oly.y predictable hearing loss will be due to presbyacusis. TBe long term aim therefore should be that NIHL in milit aircrew will become an area of historical interest ratger than current concern.

\section{REFERENCES}

1. Ramazzini B. De Morbis Artificum Diatriba; (17 f Geneva. Translated by W C Wright. Chicagg; University of Chicago Press, 1940.

2. Annual Report of the Chief Inspector of Factories Workshops. 1934, HMSO London. 
3. Noise at Work Regulations, SI No 1790. 1989, HMSO London.

4. Dickson EDD, EWing AWG, Littler TS. The Effects of Aeroplane Noise on the Auditory Acuity of Aviators. J Laryngol Otol 1939: 54; 531-543.

5. DickSON EDD. Some Effects of Intense Sound and Ultrasound on the Ear. Proc R Soc Med 1953; 46; 139-146.

6. LIFF S, GoldSTEIN JL. Hearing Impaired Aviators in the US Army. Advisory Group For Aerospace Research and Development (AGARD). Conference proceedings No. 311. June 1981.

7. Rood GM, GLen MC. A Survey of Noise Doses Received by Military Aircrew. Technical Report 77080. June 1977, HMSO London.

8. Baines DC, Cogger MK. A Survey of Noise Doses Received by the Aircrew of the Lynx AH Mk.1 Helicopter. Royal Aircraft Establishment, Technical Memorandum FS388. February 1981, HMSO London.

9. Glen MC, Moorse SA. The Contribution of Communication Signals to Noise Exposure. Royal Aircraft Establishment, Technical Report 77027. February 1977,HMSO London.

10. Peters LJ, Ford H. Extent of Hearing Loss Among Army Aviators at Fort Rucker, Alabama. US Army Aeromedical Research Laboratories, Fort Rucker, Alabama; Report No. 83-12, August 1983.

11. FitzPatrick DT. An Analysis of Noise-Induced Hearing Loss in Army Helicopter Pilots. Aviat Space Environ Med 1988; 59(10): 937-941.
12. Edgington K, Oelman BJ. An Audiometric Surve of Army Aircrew. 1982, Internal Report. HQ Director Army Air Corps, Middle Wallop, England.

13. Ribak J, Hornung S, Kark J, Froom J, Wolfsteif A, Ashenazi IE. The Association of Age, Flying Time and Aircraft Type with Hearing Loss in the Israeli Airforce. Aviat Space Environ Med 1985; 56 (4): 322-327.

14. JONES DG. An Audiological Survey of Aircrew. J Nav Med Sev, 1988; 74: 44-50.

15. LISHER BJ, PARKINSON JN. The Acoustic Performance of the Mark 4 Aircrew Protective Helmet. Royal A $\bar{B}$ Force, Institute of Aviation Medicine. Aircre

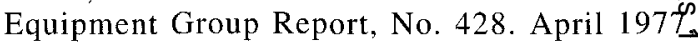
Farnborough, Hampshire.

16. RoOD GM. The Acoustic Attenuation of the Mk $\overrightarrow{\vec{\omega}}$ Flying Helmet Measured by Semi-Objective Methods. Royal Aircraft Establishment, Technic 需 Memorandum FS 171. 1978, HMSO, London.

17. Pratt RL, Roberts S, Parkinson JN. The Acoustic Attenuation of In-Flight Headgear. Royal Airforcet Institute of Aviation Medicine Report No. 603.198 Farnborough, Hampshire.

18. JAMES SH, HARPUR KMT. In-Flight Assessment of Helmet Mounted Active Noise Reduction Systempio Sea Harrier FRS1. Royal Aerospace Establishm绐 Technical Memorandum MM33. 1990, HM\& London.

19. Ministry of Defence (Current): "Army General gind Administrative Instruction (AGAI)" Vol. 2: Chap क6 Paras 339-354.

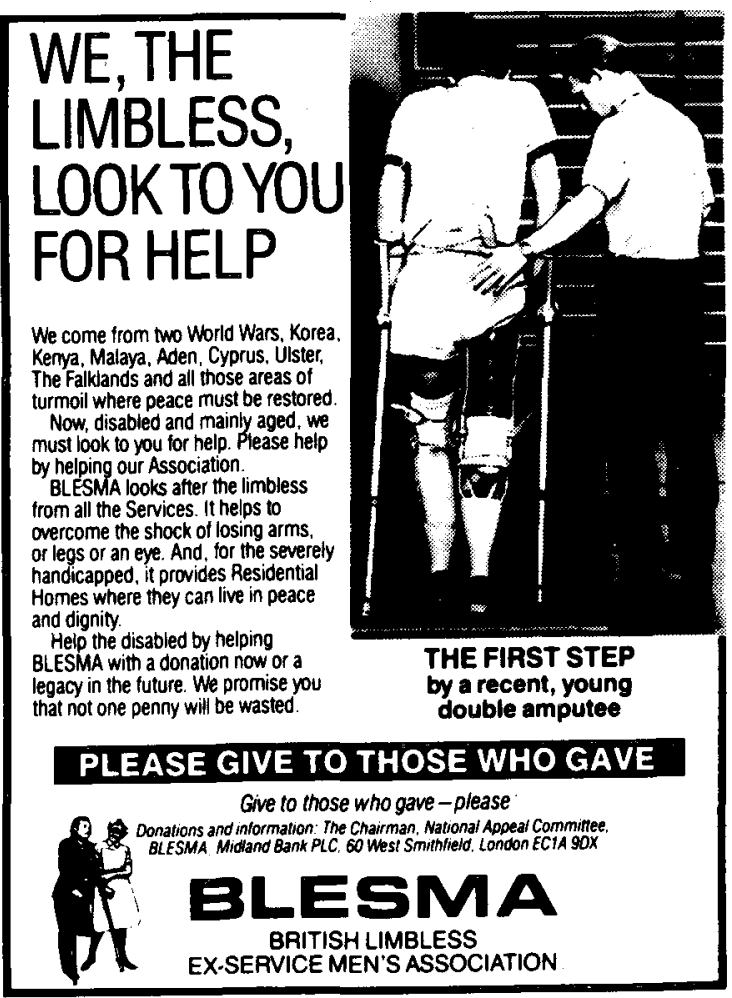

